\title{
A ÁREA DE SAÚDE DA MULHER NEGRA: CONSIDERAÇÕES SOBRE RACISMO INSTITUCIONAL
}

THE BLACK WOMEN'S HEALTH AREA: CONSIDERATIONS ON INSTITUTIONAL RACISM

Sônia Beatriz dos Santos

Como citar este artigo:

SANTOS, Sônia Beatriz dos. A área de saúde da mulher negra: considerações sobre racismo institucional. In: Cadernos do Lepaarq, v. XVI, n.31., p. 134-146, Jan-Jun. 2019. 


\title{
A área de saúde da mulher negra: considerações sobre racismo institucional
}

\author{
Sônia Beatriz dos Santos*
}

Resumo: $\mathrm{O}$ artigo discute a área de saúde da mulher negra como uma estratégia e abordagem que se contrapõe ao racismo presente nas instituições de assistência a saúde, e que têm afetado diretamente as mulheres negras (e a população negra num sentido mais amplo). A organização da área é parte de um movimento alavancado por ativistas e profissionais negras(os) e suas organizações como um campo de conhecimento e intervenção social e política que propunha em meados do século XX, um novo modelo fundado numa perspectiva racial e de gênero, para pensar e atuar na assistência em saúde, demandar o direito à saúde da mulheres, e denunciar o racismo no sistema de saúde.

\begin{abstract}
The article discusses the area of Black women's health as a strategy and approach that opposes institutional racism in health care institutions, which have directly affected Black women (and the Black population in a broader sense). The organization of the area was part of a movement leveraged by Black activists and health professionals, and their organizations as a field of knowledge and social and political intervention that proposed in the mid-twentieth century a new model based on a racial and gender perspective to think and act in health care, to demand the women's right to health, and denounce racism in the health system.
\end{abstract}

\section{Palavras Chave:}

Saúde da Mulher Negra; Racismo Institucional; Gênero; Assistência em Saúde.

\section{Keywords:}

Black Woman's Health; Institutional Racism; Gender; Health Care.

\footnotetext{
* Doutora em Antropologia pela University of Texas at Austin/ EUA; professora adjunta da Universidade do Estado do Rio de Janeiro (UERJ); pesquisadora do Núcleo de Estudos Afro-Brasileiros; e docente do Programa de Pós-Graduação em Educação, Cultura e Comunicação em Periferias Urbanas (FEBF/UERJ). E-mail: soniabsantos@yahoo.com
} 


\section{INTRODUÇÃO}

O presente artigo busca refletir sobre a área de saúde da mulher negra como uma estratégia e abordagem que se contrapõe a situações iníquas e ao racismo institucional (RI) na assistência em saúde, que afetavam diretamente as condições de saúde de mulheres negras no Brasil. Alavancada por ativistas e profissionais negras(os) e suas organizações como um campo de conhecimento e de intervenção social e política esta área propunha, a partir da segunda metade do século XX, um novo modelo, fundado numa perspectiva racial e de gênero, para pensar e atuar na assistência em saúde da mulher. Esta linha de pensamento se constituiu como resultado da luta pelo direito à saúde da mulher pleiteada pelos movimentos de mulheres nos quais o protagonismo das ativistas negras se destacava, e ainda, das reivindicações dos movimentos negros que denunciavam o racismo das instituições de saúde e de seus agentes, e exigiam os direitos da população negra ao acesso e a assistência plenos, propondo a criação e implementação de uma Política Nacional de Saúde Integral da População Negra, que foi instituída pela Portaria No. 992, de 13 de maio de 2009 (BRASIL, 2013).

É preciso destacar ainda que a criação da área de saúde da mulher negra (bem como da população negra) significou mais do que a denúncia do racismo institucional, pois na tarefa de confrontar estereótipos, imaginários, discursos e práticas racistas e generificados a partir de uma lógica heteronormativa, os grupos proponentes necessitaram construir, reconstruir e contrapor formulações epistemológicas tanto nas Ciências da Saúde quanto nas Ciências Sociais. Assim, até meados do século XX cientistas de ambos os campos - assentados no privilégio epistêmico eurocêntrico e no racismo heteropatriarcal - normatizavam, desqualificavam, subalternizavam e desautorizavam de forma hegemônica a produção de conhecimentos oriundos de profissionais, ativistas e intelectuais negras(os) em saúde. Em outras palavras, tratava-se também a partir deste projeto da denúncia e desconstrução de um racismo epistêmico que sustentava a inferioridade dos negros no campo da saúde se utilizando de ideias eugenistas, ainda que esta dimensão do racismo não fosse correntemente mencionada a época da constituição da área. Os argumentos de Oliveira (1998) evidenciam a tomada de consciência destas questões,

\footnotetext{
Os estudos sobre saúde da população negra no Brasil até meados da década de 60 do século XX, assim como em outras partes do mundo, fazem parte da perspectiva eugenista. Ou seja, integram o ideário da existência de 'raças puras e superiores'. As 'raças impuras e inferiores' foram 'estudadas' tão-somente para que pudessem ser encontradas ‘comparações científicas’ de suas ‘impurezas’ e inferioridades (OLIVEIRA, 1998, p. 94).
}

A despeito dessa concepção a autora demonstra que a saúde da população negra foi ressignificada por pesquisadoras(es) e ativistas dos movimentos negros. Lopes e Werneck (2010, p. 15) compreendem esta área "como um campo de ativismo, conhecimento, saberes e práticas, estratégias de gestão e controle social”. E para Werneck (2001, p. 7), sua reconceituação representava uma "operação estratégica de desocultamento de um campo vital para a sobrevivência de uma parcela numericamente importante da população brasileira”, demonstrando ainda que sua criação incorporava

[e]lementos de diversas áreas do conhecimento, ampliando para além da biologia e da medicina as possibilidades de leitura da gênese dos processos de saúde-doença junto à população negra e toda a população brasileira. Assim, o racismo e suas consequências; os significados de cultura (e cultura negra); análises das desigualdades sociais e seus efeitos, entre outros, são parte essencial da construção de um significado adequado às necessidades deste grupo populacional em particular. (WERNECK, 2001, p. 7).

As mulheres negras se organizam em torno dessas questões e vão formular suas agendas de enfrentamento das desigualdades no campo da saúde. Esta demanda por direitos se amplia nos anos de 1970 e 1980 ainda no interior do movimento de mulheres, período que caracterizado pelo movimento da Terceira Onda Feminista. Nesse período emergiram o 
Movimento de Libertação da Mulher, os empenhos para elaboração do conceito de patriarcado, as conferências mundiais cuja temática principal era a mulher, a institucionalização de parte do movimento feminista "e a elaboração do conceito e da teoria de gênero" (OLIVEIRA, 1998, p. 22), portanto, era um momento de grande efervescência política.

Assim, o conceito de saúde da população negra foi construído pelos próprios segmentos de mulheres negras e homens negros que reivindicavam a melhoria das condições de vida da população e demandavam ações que representassem mudanças efetivas em termos estruturais e ainda influenciassem na elaboração e monitoramento das políticas públicas, em especial aquelas direcionadas à saúde (WERNECK, 2001, p. 7). E a área de saúde da mulher negra foi estabelecida na confluência desses empreendimentos, nos quais mulheres negras de distintos segmentos traziam o foco para suas necessidades específicas em saúde, tomando como referência suas experiências com as situações de racismo, sexismo, e lesbofobia ${ }^{1}$ enfrentadas no sistema de saúde.

Este artigo foi composto em três partes. Na primeira, expomos breve conceitualização acerca do racismo institucional. Em segundo apresentamos os contextos sociopolíticos e históricos da emergência área de saúde da mulher negra, assinalando sua articulação com o enfrentamento do racismo no sistema de saúde. Na segunda parte, discutimos a relevância desta formulação para o estabelecimento de estratégias de enfrentamento das situações desiguais, em especial do racismo institucional. Concluímos pontuando a importância do movimento de mulheres negras e de seus empreendimentos na constituição de uma produção de conhecimento teórico-metodológico e de ação política acerca de suas próprias condições de saúde.

\section{O RACISMO INSTITUCIONAL}

O racismo se constitui como uma ideologia que se expressa por meio das relaç̃es interpessoais e entre grupos, no modo como se estruturam e se desenvolvem as políticas públicas e seus programas e ações de implementação, através das estruturas governamentais e não-governamentais, e no modo como os Estados se organizam para conferir direitos e benefícios e prover serviços à população. De modo que,

trata-se de um fenômeno de abrangencia ampla e complexa que penetra e participa da cultura, da política e da ética. Para isso requisita uma série de instrumentos capazes de mover os processos em favor de seus interesses e necessidades de continuidade, mantendo e perpetuando privilégios e hegemonias. Por sua ampla e complexa atuação, o racismo deve ser reconhecido também como um sistema, uma vez que se organiza e se desenvolve através de estruturas, políticas, práticas e normas capazes de definir oportunidades e valores para pessoas e populaç̃ões a partir de sua aparencia atuando em diferentes níveis: pessoal, interpessoal e institucional. (GELEDÉS, s/d: p. 11).

O sistema de saúde no Brasil tem sido identificado e questionado como um espaço de produção, reprodução e disseminação do racismo institucional, sendo este definido como,

\footnotetext{
A incapacidade coletiva de uma organização em prover um serviço apropriado ou profissional às pessoas devido à sua cor, cultura ou origem étnica. Ele pode ser visto ou detectado em processos, atitudes e comportamentos que contribuem para a discriminação através de preconceito não intencional, ignorância, desatenção e estereótipos racistas que prejudicam minorias étnicas (Comission for Racial Equality, The Stephen Lawrence Inquire Implications for Racial Equality, 1999, p. 2).
} 
WERNECK (2016) apresenta o racismo institucional como “a dimensão mais negligenciada do racismo" enfatizando que este "desloca-se da dimensão individual e instaura a dimensão estrutural, correspondendo a formas organizativas, políticas, práticas e normas que resultam em tratamentos e resultados desiguais" (p. 541). Ela o identifica como racismo sistêmico destacando que desta forma este "garante a exclusão seletiva dos grupos racialmente subordinados, atuando como alavanca importante da exclusão diferenciada de diferentes sujeitos nesses grupos (p.541-542)".

Assinala ainda que para além de se apresentar como uma insuficiência, o RI se constitui num "mecanismo performativo ou produtivo, capaz de gerar e legitimar condutas excludentes, tanto no que se refere a formas de governo quanto de accountability" (que traduzo aqui como um processo complexo que requer o compromisso de instituições, grupos e pessoas com uma postura engajada e contínua pautada na ética e responsabilidade que assegurem a vigilância e enfrentamento de situações de RI, e a disposição em promover atitudes e mecanismos antirracistas que auxiliem na prevenção e coibição deste e de seu ocultamento). E afirma que "para que seja efetivo, o RI deve dispor de plasticidade suficiente para oferecer barreiras amplas - ou precisamente singulares - de modo a permitir a realização de privilégio para uns, em detrimento de outros, em toda sua ampla diversidade" (WERNECK, 2016: p. 542).

Werneck (2016) demonstra ainda que o racismo institucional corresponderia "a ações e políticas institucionais capazes de produzir e/ou manter a vulnerabilidade de indivíduos e grupos sociais vitimados pelo racismo” (p. 543). Mas a autora enfatiza que correlacionado ao racismo existem outros fatores - tais como a subordinação de gênero, classe e baseada na orientação sexual - que co-determinam as situações de vida e saúde agravando ainda mais seus efeitos sobre as pessoas (p. 543).

Finalmente, percebemos que no nível institucional o racismo atua-em separado e/ou em intersecção com outras formas de opressão - reforçando e naturalizando formas de preconceito e discriminação que se materializam na indisponibilidade e redução do acesso a serviços e a políticas de qualidade, por fim produzindo e perpetuando desigualdades. Deste modo, o sistema de saúde - através de suas agências e agentes - tem se constituído num veículo de reprodução, internalização e enraizamento desta dimensão do racismo.

\section{CONTEXTOS SOCIOPOLÍTICOS E HISTÓRICOS}

\section{Reivindicações pela saúde das mulheres}

$\mathrm{Na}$ história das sociedades ocidentais, observamos que as mulheres afrodescendentes sempre tiveram participação expressiva nos movimentos femininos que advogavam pelos direitos das mulheres. Os anos 70, 80 e 90 foram um período de florescimento de um conjunto de ações em saúde protagonizadas por grupos femininos de distintos segmentos sociais e pertencimentos étnico-raciais. Destacamos o protagonismo do Movimento Internacional Mulher e Saúde (MIMS), que constituiu um conjunto de eventos fundamentais realizados em distintas regiões das Américas, Europa, Ásia e África. Foram eles: as conferências da ONU sobre a mulher realizadas entre 1975 e 1995, os encontros feministas latino-americanos e do Caribe que ocorreram entre 1981 e 1999, os encontros feministas brasileiros realizados entre 1979 e 1997, e os nove encontros do Movimento Internacional Mulher e Saúde (MIMS) que organizados entre 1977 e 1997 (ver Oliveira, 1998, p. 22-23).

Mas é preciso ressaltar que, a despeito das mulheres negras terem se fundamentado em alguns dos princípios do movimento feminista, elas ao mesmo tempo apresentavam severas críticas a ele por suas limitações em reconhecer as diferenças entre as mulheres dentro do próprio movimento. Assim, ponderavam que tal realidade exigia um olhar para suas necessidades específicas na agenda política do projeto feminista. Esta situação levou as ativistas negras a buscar sua própria 
organização e construir uma agenda própria que refletisse suas necessidades e especificidades. Tal posicionamento crítico ao movimento tradicional de mulheres se configurou mais visivelmente na Terceira Onda Feminista, na qual se ampliava a participação de mulheres não brancas, trabalhadoras das classes populares, trabalhadoras rurais, mulheres lésbicas, entre outros segmentos marginalizados e atingidos pela exclusão social crescente.

A luta feminista pela saúde da mulher no Brasil compreende estas influências sociais e históricas, e este legado resultou em ações cruciais que marcaram o campo de luta do movimento em geral e, em específico, das negras, e dentre as quais destacamos algumas a seguir. A primeira foi a criação do Programa de Assistência Integral à Saúde da Mulher (PAISM) em 1983, e adotado pelo governo brasileiro em 1985 e cuja proposta se constituía no atendimento às mulheres de modo integral, levando-se em consideração todas as fases de sua vida: infância, adolescência, idade adulta e terceira idade. O programa reorganizou a assistência à mulher no país e favoreceu uma conceituação crítica da saúde e dos direitos sexuais e reprodutivos (OLIVEIRA, 1998, p. 30-31). Entretanto, como revelou Oliveira (1998, p. 43), o PAISM ficou na "boa intenção" e não foi de fato implementado em sua totalidade no sistema de saúde, situação que perdura até os dias atuais.

Uma segunda ação fundamental foi a criação da RedeSaúde / Rede Nacional Feminista de Saúde e Direitos Reprodutivos em 1991, que reunia grupos e mulheres que atuavam e/ou trabalhavam na área de saúde e direitos reprodutivos e sexuais, objetivando apoiar e dar visibilidade política à luta das mulheres pela saúde sob o ponto de vista feminista, além de promover a "participação de mulheres e organizações feministas" na elaboração de políticas públicas e sociais em saúde (OLIVEIRA, 1998, p. 33).

Em terceiro lugar, fundou-se em 1991 a Comissão de Cidadania e Reprodução (CCR), uma instituição multidisciplinar em defesa do exercício do direito individual em termos da reprodução humana em consonância com as declarações da Organização das Nações Unidas (ONU), em especial da Convenção pela Eliminação de Todas as Formas de Discriminação contra a Mulher (OLIVEIRA, 1998, p. 35).

Em quarto lugar, criou-se em 1992 o Programa Saúde Reprodutiva da Mulher Negra do Centro Brasileiro de Análise e Planejamento (CEBRAP), que congregava atividades na área de população e sociedade e oferecia formação em pesquisa na área de saúde da população negra (OLIVEIRA, 1998, p. 36).

E, finalmente, destacam-se os investimentos de fortalecimento e proteção aos direitos sexuais e reprodutivos entre os anos de 1970, 1980 e 1990, que expuseram o problema das altas taxas de mortalidade materna no país e revelaram que os segmentos mais afetados se constituíam em mulheres jovens, pobres, do Nordeste e do Norte do país, e, em termos étnicoraciais, em mulheres negras e indígenas. Diagnósticos produzidos nesses períodos revelavam também que a maioria das mortes era evitável, pois eram provocadas por "hipertensão arterial durante a gravidez, infecções, hemorragias, desatenção e/ou atenção inadequada à mulher em situação de aborto, por descumprimento do direito ao aborto previsto em lei nos casos de estupro e risco à vida da gestante, pela criminalização do aborto, por cesarianas desnecessárias, dentre outros abusos" (OLIVEIRA, 1998, p. 40-41).

Tais circunstância sobre a situação da saúde e dos direitos reprodutivos desses segmentos femininos desencadeou uma série de ações por parte do movimento de ativistas negras para buscar prevenir e reverter esse quadro de adoecimento e mortalidade. O movimento demandava uma intervenção crítica a partir: (1) da formação de comitês de prevenção à mortalidade materna nas secretarias de saúde para enfrentar esta situação, denunciada como genocídio, e (2) da implantação do Sistema Único de Saúde (SUS), do Programa de Assistência Integral à Saúde da Mulher (PAISM) e do serviço de aborto legal (OLIVEIRA, 1998, p. 41). 
Diversas redes de saúde da mulher foram criadas entre o final da década de 1970 e o início da década de 1990 , entre as quais estão: a Rede Global de Mulheres pelos Direitos Reprodutivos (WGNRR) ou Rede Mundial de Mulheres pelos Direitos Reprodutivos (RMMDR), em 1978; a Rede de Saúde das Mulheres Latino-Americanas e do Caribe, em 1984; e a Rede Nacional Feminista de Saúde e Direitos Reprodutivos, em 1991 (OLIVEIRA, 1998, p. 42). Portanto, todas estas ações realizadas pelo movimento de mulheres corroboraram para a organização das mulheres negras em torno de estratégias de enfrentamento do racismo institucional e que assegurassem seus direitos em saúde, a exemplo da criação da área de saúde da mulher negra.

\section{As reivindicações do Movimento Negro pelo direito à saúde}

O enfrentamento do racismo institucional, bem como as reivindicações dos negros, sobretudo das mulheres negras por melhores condições de saúde é antiga no Brasil. Segundo Lopes e Werneck (2010, p. 7) “o histórico de constituição de sistemas de atenção à saúde da população brasileira pode ser percebido como o percurso das lutas empreendidas pela população excluída, onde sempre esteve a população negra, por atenção e participação". As autoras demonstram que os negros sempre estiveram à margem do acesso aos serviços, políticas e programas de saúde no país; e revelam a existência de estratégias de exclusão dos negros na organização dos vários modelos de atenção à saúde ${ }^{2}$ adotados pelo Estado brasileiro ao longo da história, circunstâncias que evidenciam o racismo corporificado pelas instituições como uma realidade sustentada pelo Estado brasileiro. Antes de 1988, apenas quem possuía vínculos formais de trabalho - carteira assinada, um registro formal - poderia acessar o sistema de saúde no país, e somente uma parcela pequena de negras e negros tinha condições de usufruir destes benefícios. Outro aspecto é que os serviços de saúde eram quase inexistentes nas regiões habitadas predominantemente pela população negra (LOPES; WERNECK, 2010, p.7).

WERNECK (2016) ressalta que,

As reivindicações da população negra e de movimentos sociais - especialmente o Movimento de Mulheres Negras e do Movimento Negro - por mais e melhor acesso ao sistema de saúde participaram da esfera pública ao longo dos vários períodos da história das mobilizações negras, principalmente no período pós-abolição, e se intensificaram na segunda metade do século XX, com forte expressão nos movimentos populares de saúde, chegando a participar dos processos que geraram a Reforma Sanitária e a criação do Sistema Único de Saúde. No entanto, é possível verificar que essa presença, apesar de ter contribuído para a concepção de um sistema universal de saúde com integralidade, equidade e participação social, não foi suficiente para inserir, no novo Sistema, mecanismos explícitos de superação das barreiras enfrentadas pela população negra no acesso à saúde, particularmente aquelas interpostas pelo racismo (p. 536).

O século XX foi marcado por debates críticos pela mobilização de diversos grupos da sociedade civil em defesa de direitos, entre os quais se encontram os esforços e estratégias adotadas por grupos negros para o enfrentamento do racismo. Em conjunto com outros setores do movimento social e com os profissionais de saúde, ativistas do movimento negro reuniram esforços para elaborar uma nova concepção de saúde na Constituição Brasileira de 1988, que a institui como direito universal (Art. 196).

2 Santas Casas de Misericórdia (a partir de 1582), Caixas de Aposentadorias e Pensões/ CAPs (1923), Institutos de Aposentadoria e Pensões/ IAPs (1926), Serviço de Assistência Médica Domiciliar/ SAMDU (1949), Instituto Nacional de Previdência Social/ INPS (1966), Plano de Pronta Ação/ PPA (1968), Instituto Nacional de Assistência Médica da Previdência Social/ INAMPS (1974), Sistema Nacional de Saúde (1975), Programa de Interiorização de Ações de Saúde e Saneamento/ PIASS (1976), Programa de Desenvolvimento de Sistemas Unificados e Descentralizados de Saúde nos Estados/ SUDS (1987) (LOPES; WERNECK, 2010, p. 7). 
A Constituição de 1988 foi afirmativa no que se refere aos avanços na área da saúde e ainda criou instrumentos legais para confrontar o preconceito de qualquer natureza - de origem, raça, sexo, cor, idade e quaisquer outras formas de discriminação (BRASIL, 1988, art. $3^{\circ}$, IV). Foi a partir desta orientação social, cujo horizonte era a promoção do bem-estar de todas as pessoas, que se formulou o Sistema Único de Saúde (SUS), o qual representava uma "política de Estado para garantir a saúde como um direito efetivo para todas e todos" (LOPES; WERNECK, 2010, p. 9).

Ativistas negras e negros se apropriavam desse momento socio-histórico de mudanças na concepção e no acesso à saúde para garantir os direitos da população negra, denunciando suas condições de morbidade e mortalidade. É no contexto de formulação desta nova perspectiva concebida na sociedade brasileira que a noção de saúde da população negra passa a ser utilizada nos anos 80 pelo movimento negro. E nos anos 90 esta ideia é aprimorada pelo movimento de mulheres negras para atender às suas especificidades. Lopes e Werneck (2010, p. 8-9) enfatizam que "esta noção está orientada pela análise sistemática das desigualdades raciais em saúde e no julgamento de que sua manutenção, ao longo dos séculos, é determinada pelo racismo e outras formas de inferiorização social a ele associadas."

O conceito de saúde da população negra é elaborado, portanto, a partir do momento em que ativistas, pesquisadoras(es), profissionais de saúde, gestoras(es) negras(os), em sua maioria mulheres, e outros atores políticos dirigiram suas ações na busca por equidade em saúde e identificaram o racismo e a discriminação racial como fatores determinantes das condições de saúde (LOPES; WERNECK, 2010, p. 9). Desta forma, as autoras definem a saúde da população negra como um “campo de produção de conhecimento e saberes, atitudes, práticas e estratégias de gestão" que "é construído e aprimorado a partir da necessidade de compreender e intervir nos impactos do racismo sobre a saúde das pessoas, em particular de negras e negros, de confrontá-los e superá-los como pressuposto para a consecução de uma sociedade efetivamente democrática, menos desigual e injusta" (LOPES; WERNECK, 2010, p. 9).

Lopes e Werneck (2010, p. 10-14) afirmam que desde 1990 o movimento de mulheres negras vinha protagonizando ações para a conquista do direito à saúde no país sob a perspectiva do racismo e do sexismo. Destacam-se:

a) 1990: Campanha Nacional contra a Esterilização em Massa de Mulheres Negras;

b) 1991: grupos religiosos de matrizes africanas se organizam para enfrentar a epidemia de HIV/Aids;

c) 1995: Na Marcha Zumbi dos Palmares contra o Racismo, pela Cidadania e pela Vida grupos negros exigiram do governo federal ações que foram posteriormente implantadas em 1996: inclusão do quesito cor nas declarações de nascidos vivos e de óbito, nos sistemas de informação sobre mortalidade (SIM) e nascidos vivos (SINASC), e nos dados de identificação dos sujeitos das pesquisas (resolução no. 196/96);

d) 2001: elaboração da Política Nacional de Saúde da População Negra;

e) 2001: Programa de Combate ao Racismo Institucional / PCRI (LOPES; QUINTILIANO, 2007);

f) 2003: participação na $12^{\mathrm{a}}$ Conferência Nacional de Saúde garantindo aprovação de deliberações que contemplavam a perspectiva racial, de gênero e geração, dentre outras demandas;

g) 2004: instituição do Comitê Técnico de Saúde da População Negra / CTSPN;

h) 2004: organização do Seminário Nacional de Saúde da População Negra;

i) 2005: Conferência Nacional de Ciência e Tecnologia (subagenda Saúde da População Negra, para investimentos e pesquisas). E ocorreram ainda: (1) a ampliação da participação de negras e negros nos espaços formais de controle social; (2) regulamentação da Política Nacional de Atenção Integral às Pessoas com Doença Falciforme; (3) estabelecimento do dia 27 de outubro como o Dia Nacional de Mobilização Pró-Saúde da População Negra;

j) 2007: realização da $13^{\text {a }}$ Conferência Nacional de Saúde; 
k) 2008: instalação da Comissão Intersetorial de Saúde da População Negra no Conselho Nacional de Saúde (Resolução No. 393 de 22 de fevereiro de 2008).

A partir do que foi exposto, observamos que as cronologias das reivindicações contemporâneas das mulheres negras pela saúde nos permitem evidenciar os contextos de surgimento da área de saúde da mulher negra, e ainda como o problema do racismo institucional perpassa por todas as conjunturas expostas. Nos últimos 28 anos, as mobilizações políticas promovidas por redes de articulações nacionais e locais têm se dedicado ao desenvolvimento dessas discussões e ao controle social das políticas públicas de saúde, com foco no enfrentamento do racismo e na promoção da equidade. Neste sentido, um dos mais relevantes projetos de intervenção quanto aos efeitos do racismo institucional, se constituiu na criação do Programa de Combate ao Racismo Institucional no Brasil (PCRI) ${ }^{3}$, um trabalho organizado regionalmente para discutir questões relacionadas a raça/ etnia e objetivava "apoiar, de forma integrada, o setor público no combate e prevenção ao racismo institucional e a sociedade civil na avaliação e monitoramento desse processo" (p.1).

As organizações de mulheres negras estiveram fortemente articuladas com o PCRI, sobretudo porque já apresentavam como pudemos evidenciar larga experiência no enfrentamento do racismo nas instituições de saúde no Brasil. Por fim, como um campo de conhecimento e ação, a área de saúde da mulher negra vai fomentar um modelo de pensar e atuar na assistência em saúde fundado numa perspectiva racial e de gênero, uma abordagem crucial que vai conferir ainda mais visibilidade sobre as peculiaridades e os efeitos do racismo institucional sobre as mulheres negras.

\title{
A saúde da mulher negra: a relevância desta formulação
}

Jurema Werneck (2016) argumenta que,

\begin{abstract}
A saúde da mulher negra não é uma área de conhecimento ou um campo relevante nas Ciências da Saúde. É inexpressiva a produção de conhecimento cientifico nessa área e o tema não participa do currículo dos diferentes cursos de graduação e pós-graduação em saúde, com raríssimas exceções. Trata-se de assunto vago que, na maior parte dos casos, é ignorado pela maioria de pesquisadoras e pesquisadores, estudantes e profissionais de saúde no Brasil (p.535).
\end{abstract}

Assim, em seu artigo WERNECK (2016) revela tal realidade e enfatiza a necessidade de subsídios para pesquisas na área, bem como a elaboração de ações que contribuam para "a formulação e gestão de políticas públicas adequadas às necessidades expressas nos indicadores sociais e de saúde das mulheres negras brasileiras” (p.535).

Considerando as discussões anteriores aos anos 2000, observamos que as(os) proponentes da área de saúde da mulher negra já se depararam com um cenário favorável para a formulação de suas bases, devido às lutas empenhadas pelos movimentos de mulheres e negros e, em especial, pelo desenvolvimento da ideia de uma política de saúde da população negra enquanto conceito, instrumento político e ação política, que denunciava e se contrapunha veementemente ao racismo no sistema de saúde e consequentemente em suas instituições. Tais experiências auxiliaram o movimento de mulheres negras a identificar e qualificar os indicadores em saúde que evidenciassem suas especificidades, bem como a compreender e dimensionar os impactos da discriminação racial e de gênero nas suas condições de saúde. O grupo também denunciava os efeitos do racismo na produção de enfermidades e ainda a necessidade de discutir o que denominavam de doenças raciais/étnicas. Segundo

3 Parceria entre a Agência de Cooperação Técnica do Ministério Britânico para o Desenvolvimento Internacional e Redução da Pobreza (DFID), o Ministério da Saúde (MS), a Secretaria Especial de Políticas para Promoção da Igualdade Racial (Seppir), o Ministério Público Federal (MPF), a Organização Panamericana de Saúde (Opas) e o Programa das Nações Unidas para o Desenvolvimento (PNUD). 
Oliveira (1998), as ativistas passaram a adotar tal perspectiva política junto às reuniões estaduais e municipais brasileiras preparatórias para os encontros mundiais.

Sobre esse período embrionário da criação de uma concepção de saúde voltada para as mulheres e a população negra em geral, Oliveira (1998) destacava a ausência de uma reflexão que auxiliasse na "compreensão da dimensão das diferenças e diferenciais raciais/étnicos, da opressão de gênero e do racismo na manutenção, recuperação e perda da saúde, em uma sociedade classista" (...) exemplificando tal lacuna a partir das contestações sobre "o quesito cor - a identificação racial", indicado por ela como "um problema/desafio nos meios científicos, entre profissionais, serviços, formuladores e implementadores das políticas de saúde” (OLIVEIRA, 1998, p. 43). E prossegue assinalando que:

Em meio a estas polêmicas os dados sobre a saúde da mulher negra brasileira são incipientes e a maioria das nossas
"especificidades" (condições biológicas e doenças), são conhecidas por nós através dos dados de outros países.
Indicadores de saúde que consideram que cor ou raça/etnia são absolutamente necessários para que possamos
avaliar a qualidade de vida dos grupos populacionais raciais ou étnicos; de que adoecem, como adoecem e de que
morrem. Ou seja, nos fornecem dados mais confiáveis e reais da morbidade e da mortalidade (OLIVEIRA, 1998,
p. 43-44).

Para a autora, não faltavam exemplos que justificassem a necessidade de se considerar o recorte racial em saúde, como a comprovada alta incidência de miomas entre as mulheres negras; a existência da anemia falciforme, considerada a doença genética mais comum entre afrodescendentes; e a hipertensão arterial, que é a causa direta ou indireta de muitas mortes no Brasil e de grande incidência entre os negros, em particular as mulheres. São circunstâncias que levavam a autora a defender a adoção de práticas mais colaborativas e preventivas no campo médico. Ela própria enquanto médica negra afirmava:

Nos interessa que a epidemiologia e a medicina como um todo trilhe o caminho, da tentativa e do esforço, de buscar
incorporar ao seu arsenal de análise as diferenças biológicas e as desigualdades sociais, oriundas da opressão de
gênero, da opressão racial/étnica e da inserção nas classes sociais. Como dizem Mary Basset e Nancy Krieger:
"(...) está bastante evidente que precisamos de novos enfoques para compreender a interpenetração do racismo, das
relações de classe e saúde” (OLIVEIRA, 1998, p. 44).

Se valendo mais uma vez de suas considerações, sua proposta era a de que as mulheres negras investissem no enfrentamento da discriminação e das atitudes controlistas e abusivas dos médicos sobre a população negra, em particular sobre as mulheres, atitudes justificadas pelas novas teorizações e reciclagens do racismo científico e do determinismo biológico que emergem no século XX, "fazendo política e fazendo ciência" (OLIVEIRA, 1998, p. 45).

Werneck (2001) argumentava que a Saúde da Mulher Negra é "uma linha de conhecimento e ação que se origina no reconhecimento da multiplicidade de fatores que agem sobre os processos de saúde/doença, como também da multiplicidade de situações favoráveis e desfavoráveis que são vividas pelas mulheres negras brasileiras” (WERNECK, 2001, p. 14). E enfatiza ainda que a linha se delineia a partir “[d]o cruzamento de relações e dilemas sociais, junto a aspectos culturais, econômicos, conjunturais ou estruturais [...], incorporando [...] saberes oriundos de diversas áreas de conhecimento, ao lado de tradições e culturas diversas que influenciam a definição do que uma pessoa é, seus papéis sociais, seu grau de aceitação e de poder de agenciamento das várias realidades" (WERNECK, 2001, p. 14).

De um modo geral, o amadurecimento da ação política de ativistas negras e negros na área da saúde no Brasil favoreceu o estabelecimento e desenvolvimento das áreas de conhecimento da saúde da população negra e das mulheres negras, em especial a partir das décadas de 80 e 90. Este movimento em âmbito nacional e internacional trouxe para o centro das discussões do governo e da sociedade civil a necessidade de se pensar a saúde para além da dimensão biológica, agregando 
as influências de problemáticas sociais como as desigualdades raciais/étnicas e de gênero na assistência em saúde.

Finalmente, é crucial destacar que a promoção da saúde da mulher negra tem revelado dimensões da discriminação racial e de gênero que eram invisíveis aos modelos de análise e produção de conhecimento no campo da saúde existentes até então. O movimento de evidenciar as desigualdades em saúde se constitui em uma das principais ações do movimento de mulheres negras até os dias atuais, tanto no plano da ação política quanto no plano da produção de conhecimento, e tem sido sem dúvidas um passo crucial no enfrentamento histórico e cotidiano do racismo institucional no país.

\section{CONSIDERAÇÕES FINAIS}

Compreendemos os conceitos de saúde da população negra e da mulher negra como ideias e intervenções que foram construídas no processo de luta dos movimentos negros, em particular das ativistas e feministas negras. Tais movimentos foram fundamentais na organização da sociedade civil, em especial os grupos negros, contra o racismo no sistema de saúde por todo o país. Entre os diversos temas presentes nas pautas políticas destes grupos, destacaram-se:

a) a compreensão das noções e construções de raça e etnia;

b) a reflexão acerca de ideologias e práticas racistas oriundas das ciências biológicas e das biociências, cujas elaborações científicas construíram e sustentaram durante os séculos XVIII e XIX a inferioridade genética e física dos negros, ideias que continuaram a influenciar nos séculos XX e XXI as práticas e discursos de instituições públicas e privadas da saúde - na assistência e/ou na formação profissional evidenciando a necessidade de desconstrução destes paradigmas e processos;

c) a problematização e compreensão do que são racismo e sexismo, suas causas e efeitos sobre a população e as mulheres negras;

d) o debate sobre o direito à diferença, à igualdade e à equidade em saúde;

e) as formas de exclusão, violência e vulnerabilidade em saúde que impactam a vida da população e das mulheres negras em particular.

Neste artigo buscamos refletir sobre a constituição da área de Saúde da Mulher Negra como um campo de conhecimento e ação política e sobre a sua relevância para as lutas do movimento de mulheres negras no enfrentamento das desigualdades em saúde, e em particular do racismo institucional no Brasil que acirra ainda mais a produção de iniquidades e injustiças sociais contra a população negra. Procuramos inicialmente contextualizar esse processo de construção demonstrando as influências do movimento de mulheres e do movimento negro, em especial das ativistas e feministas. Em seguida, discutimos a linha de saúde da mulher negra enquanto um novo modelo de compreensão dos efeitos das discriminações raciais e de gênero em saúde.

Em 2013 a ONU Mulheres em parcerias com outras organizações de mulheres brasileiras (em especial negras) e a Secretaria de Políticas para as Mulheres da Presidência da República (SPM/PR) organizou o Guia de Enfrentamento ao Racismo Institucional. A publicação propõe definir e identificar o racismo institucional e como enfrentá-lo. E foi elaborado como uma ferramenta para que instituições públicas, organizações e empresas pudessem se auto avaliar e construir diagnósticos, indicadores e estratégias que auxiliem no fortalecimento de ações junto ao Estado e sociedade brasileiros para o enfrentamento do racismo institucional, que impacta o cotidiano da população negra no país. Adicionalmente, a publicação promove a igualdade de gênero, raça e etnia visando em especial o fortalecimento das mulheres (Geledés 2013: p. 8). 
Concluímos enfatizando que as mobilizações e discussões acerca da saúde da mulher negra, sobretudo no que se refere à saúde sexual e reprodutiva, têm se constituído em núcleos de produção de conhecimento teórico-metodológico e de ação política. Esta linha de pensamento e ação representa um dos maiores legados do movimento de mulheres negras para a sociedade brasileira. Empreendimento que pode ser compreendido como inovações epistemológicas em termos de produção de conhecimento e de elaboração de estratégias de intervenção no campo da política pública em saúde. 


\section{REFERÊNCIAS BIBLIOGRÁFICAS}

AYRES, J. C. R. M. et al. O conceito de vulnerabilidade e as práticas de saúde: novas perspectivas e desafios. In: CZERESNIA, D.; FREITAS, C. M. de. Promoção da saúde: conceitos, reflexões, tendências. Rio de Janeiro: Fiocruz, 2003. p. 117 140.

BRASIL. Constituição (1988). Constituição da República Federativa do Brasil. Brasília, DF: Senado, 1988.140 p.

BRASIL. Ministério da Saúde. Secretaria de Gestão Estratégica e Participativa. Departamento de Apoio à Gestão Participativa. Política Nacional de Saúde Integral da População Negra: uma política para o SUS / Ministério da Saúde, Secretaria de Gestão Estratégica e Participativa, Departamento de Apoio à Gestão Participativa. $\square$ 2. ed. $\square$ Brasília: Editora do Ministério da Saúde, 2013. 36 p. Disponível em: http://bvsms.saude.gov.br/bvs/publicacoes/politica_nacional_ saude_integral_populacao.pdf. Acesso em: 8 setembro 2018.

COOK et al. The Stephen Lawrence Inquiry. Report of an Inquiry by Sir William Macpherson of Cluny. Advised by Tom Cook, the Right Reverend Dr. John Sentamu, Dr. Richard Stone. Presented to Parliament by the Secretary of State for the Home Department by Command of Her Majesty. February 1999 (Cm 4262-I). Disponível em: https://assets.publishing.service.gov.uk/government/uploads/system/uploads/attachment_data/file/277111/4262. pdf. Acesso em: 29/12/2018.

DFID. Programa de Combate ao Racismo Institucional. Boletim Eletrônico Componente Saúde No 2 Março - Abril $\square 2005$.

Geledés. Guia de Enfrentamento do Racismo Institucional. Realização: Geledés $\square$ Instituto da Mulher Negra; Coordenação: Geledés $\square$ Instituto da Mulher Negra e Cfemea $\square$ Centro Feminista de Estudos e Assessoria. Com o apoio do Fundo para a Igualdade de Gênero da ONU Mulheres, s/d.

Disponível em: http://www.onumulheres.org.br/wp-content/uploads/2013/12/Guia-de-enfrentamento-ao-racismoinstitucional.pdf, Acesso em: 28/08/2017.

LOPES, Fernanda; WERNECK, Jurema. Saúde da população negra: da conceituação às políticas públicas de direito. In: WERNECK, Jurema. (Org.). Mulheres negras: um olhar sobre as lutas sociais e as políticas públicas no Brasil. Rio de Janeiro: Criola e Fundação Heinrich Böll, 2010. p. 5-23.

LOPES, Fernanda; QUINTILIANO, Rachel. Racismo institucional e o direito humano à saúde. Democracia Viva, $2007, \mathrm{n}$. 34 , p. $8-16$.

OLIVEIRA, Fátima. Oficinas mulher negra e saúde. Belo Horizonte: Mazza, 1998.

WERNECK, Jurema. Racismo institucional e saúde da população negra. Saude soc., São Paulo, v. 25, n. 3, p. 535-549, Sept.2016. Available from http://www.scielo.br/scielo.php?script=sci_arttext\&pid=S0104-12902016000300535\&ln $\mathrm{g}=\mathrm{en} \& \mathrm{nrm}=$ iso. access on 31 Dec. 2018.

WERNECK, Jurema. Saúde da Mulher Negra. Cadernos Criola. Rio de Janeiro: Ed. Criola. Apoio: Public Welfare Foundation e Bird, 2001.

. Saúde da população negra: passo a passo, defesa, monitoramento e avaliação de políticas públicas. Rio de Janeiro: Criola e Fundação Heinrich Böll, 2010. 